\title{
Meandering vessel on a chest radiograph in a cyanotic neonate: rare presentation of intrapulmonary course of right vertical vein in patients with supracardiac total anomalous pulmonary venous connection
}

\author{
Venkatraman Bhat ${ }^{1}$, Karthik Gadabanahalli ${ }^{1}$, Shreesha Maiya ${ }^{2}$ \\ ${ }^{1}$ Department of Radiology, Narayana Health, Bengaluru, India; ${ }^{2}$ Department of Non-invasive Cardiology, Narayana Hrudayalaya, Bengaluru, India \\ Correspondence to: Dr. Venkatraman Bhat. 309, Greenwoods Apt, Royal Gardenia, Bommasandra, Bengaluru 99, India. Email: bvenkatraman@gmail.com.
}

Submitted Dec 16, 2017. Accepted for publication Apr 12, 2018.

doi: 10.21037/qims.2018.04.04

View this article at: http://dx.doi.org/10.21037/qims.2018.04.04

\section{Introduction}

In most cases of supracardiac TAPVC typically there is confluence of pulmonary veins behind the heart on left side, constituting a left vertical vein which joins the left brachiocephalic vein thus establishing systemic communication (1). All the vascular pathways including the point of confluence of pulmonary veins, often remain within the mediastinum. It is extremely uncommon for the common pulmonary vein to cross to right side to form a right vertical vein $(2,3)$. On reviewing our cases and the illustrated cases in literature, it appears that right vertical vein has a tendency to have a short intrapulmonary course before reaching the superior vena cava. When right vertical vein has intrapulmonary course, it is evident as a faintly visualised tortuous meandering vascular channel on plain radiography. Such examples are not highlighted in the literature. We describe the features of two such cases demonstrating appearance on plain radiography and CT imaging. Brief review of literature and relevant embryology is presented.

\section{Report}

Case 1: a 35-day-old male patient with cyanosis and neonatal seizures since birth was investigated with echocardiography. Clinical examination was unremarkable apart from cyanosis. Echocardiographic examination revealed levocardia, persistent foramen ovale with a right- to-left shunt and right ventricular dilation with severe PAH. Left ventricular function was good. Also total anomalous pulmonary venous drainage with possible obstruction was suspected. CT imaging was recommended for demonstration of precise anatomy of the pulmonary veins. On plain chest radiography abnormal vascular structure was noted in the right paracardiac area mimicking a 'scimitar vein' (Figure 1A-open arrow). Vessel was posterior in location, showed meandering course in the lateral view (Figure $1 B$-open arrow). CT examination demonstrated confluence of the pulmonary veins behind the heart, to the left of the spine leading to the origin of the common vein, which showed a right-sided tortuous intrapulmonary course (Figure 1C,D,E) before reaching the superior vena cava from the right side. Intrapulmonary course of the tortuous common vein within the right lung was best shown in reconstructed MIP images (Figure 1C). Confluence of the pulmonary veins (white arrow) was well demonstrated in the axial 3-D reconstruction (Figure 1D). Apart from a mild compression of the vein while crossing the midline, no area of vascular narrowing was demonstrated. Broncho-pulmonary anatomy and visceral situs were normal

Case 2: a 2-year-old male patient was investigated for breathlessness on normal activity. Clinical and echo examination revealed a cyanotic boy with echocardiography evidence of $\mathrm{AV}$ discordance, double outlet right ventricle, ventricular septal defect, ASD and pulmonary stenosis. Pulmonary veins appeared to form a common channel, 

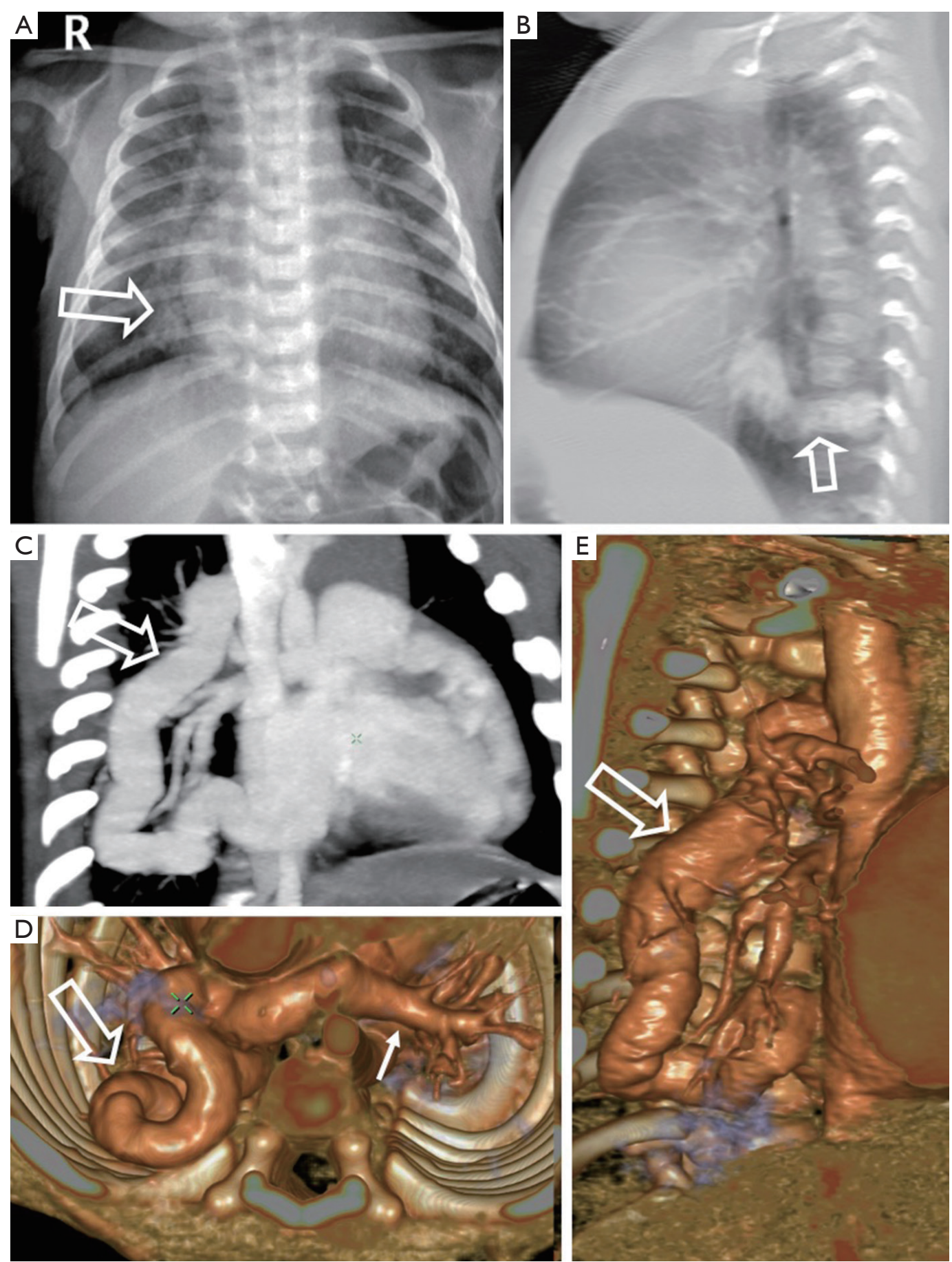

Figure 1 Frontal and lateral chest radiographs (A,B) demonstrate a faint band like opacity in right lower lung field with a tortuous course in lateral view (open arrow). CT examination (coronal MIP, axial and coronal 3D) demonstrates confluence of all the pulmonary veins behind the heart, to the left of the spine with the origin of the common-vein showing a right-sided, tortuous intrapulmonary course (C,D,E) before reaching the superior vena cava from right side $(\mathrm{E})$. Intrapulmonary course of the tortuous common-vein within the right lung is shown in the MIP examination (C). 

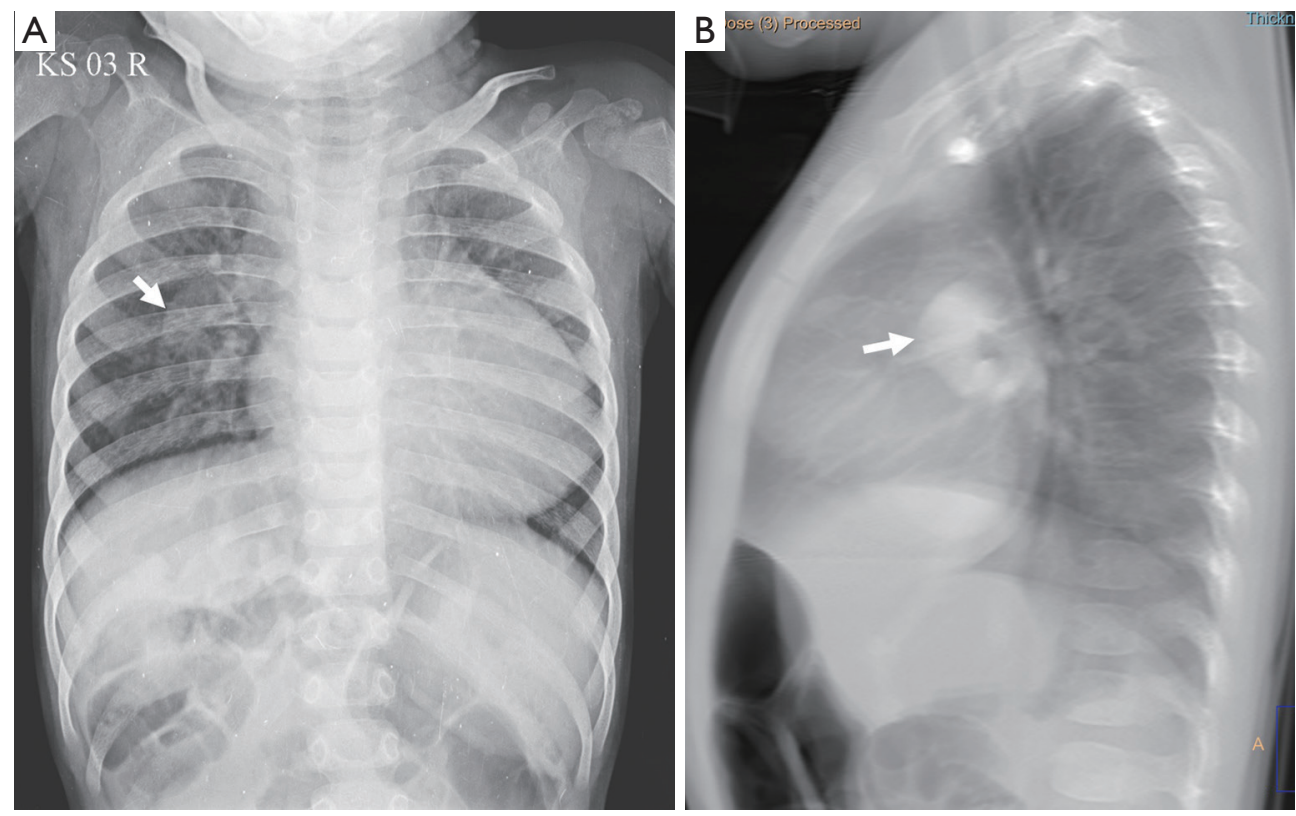

Figure 2 Chest radiograph reveal a faintly opaque curved opacity at right mid zone best seen in lateral projection (white arrow).

though there was no clear demonstration of the left vertical vein. CT evaluation was recommended to exclude supracardiac total anomalous pulmonary venous connection. CT examination confirmed supra-cardiac TAPVC with the vertical vein traversing behind the heart to right side and joining SVC after a short intrapulmonary course (Figures 2,3). Additionally double outlet right ventricle (DORV), ostium secundum ASD, inlet ventricular septal defect were noted. Hypoplastic left ventricle, dilated right atrium and ventricle were also observed. Aortic arch was left sided, showed normal branching pattern. Both lungs were trilobed. Liver was midline in location and there was no spleen. Overall findings favoured heterodoxy syndrome with right sided isomerism in association with TAPVC.

\section{Discussion}

These two patients demonstrate a unique course taken by the right vertical vein in supracardiac TAPVC. Although anomalous vein is located in extra-plural space, gross invagination of the vein in to the lung parenchyma gives an impression of intrapulmonary location on imaging. In both patients there was faint visualisation of the vein as a meandering vascular structure in right lung field on plain radiography. In the first patient vascular structure was somewhat low in location, simulating the scimitar vein (pseudo scimitar sign), as classically observed in patients with partial infra-diaphragmatic APVC. In the second patient right vertical vein was shorter, taking a peripherally convex intrapulmonary course in the right lung. Though vessels were visualised in the frontal views, it was more evident on lateral projection. Rare, less obvious examples of similar entities are noted in literature, one such documentation has been made in an angiographic study (2) and another with CT imaging (3). There is also a CT imaging description of a case of right vertical vein traversing right chest cavity along the costo-vertebral gutter without intrapulmonary invagination (4). However in none of these cases there are any plain film abnormality reported. As for author's knowledge no such demonstration of 'intrapulmonary course' of the anomalous venous anatomy in TAPVC is documented in the CT imaging literature $(2,3)$.

On the basis of embryology anomalous pulmonary venous connection is a result of common pulmonary vein becoming atretic, either partially or completely and further establishing connections of the pulmonary components of the splanchnic plexus to the paired common-cardinal and umbilical vitelline system of veins. Connections of the common pulmonary channel can either be established on left or right side (1). There is no clear embryological explanation regarding the intrapulmonary course of the vessel. It is likely to be related to the length of the right 

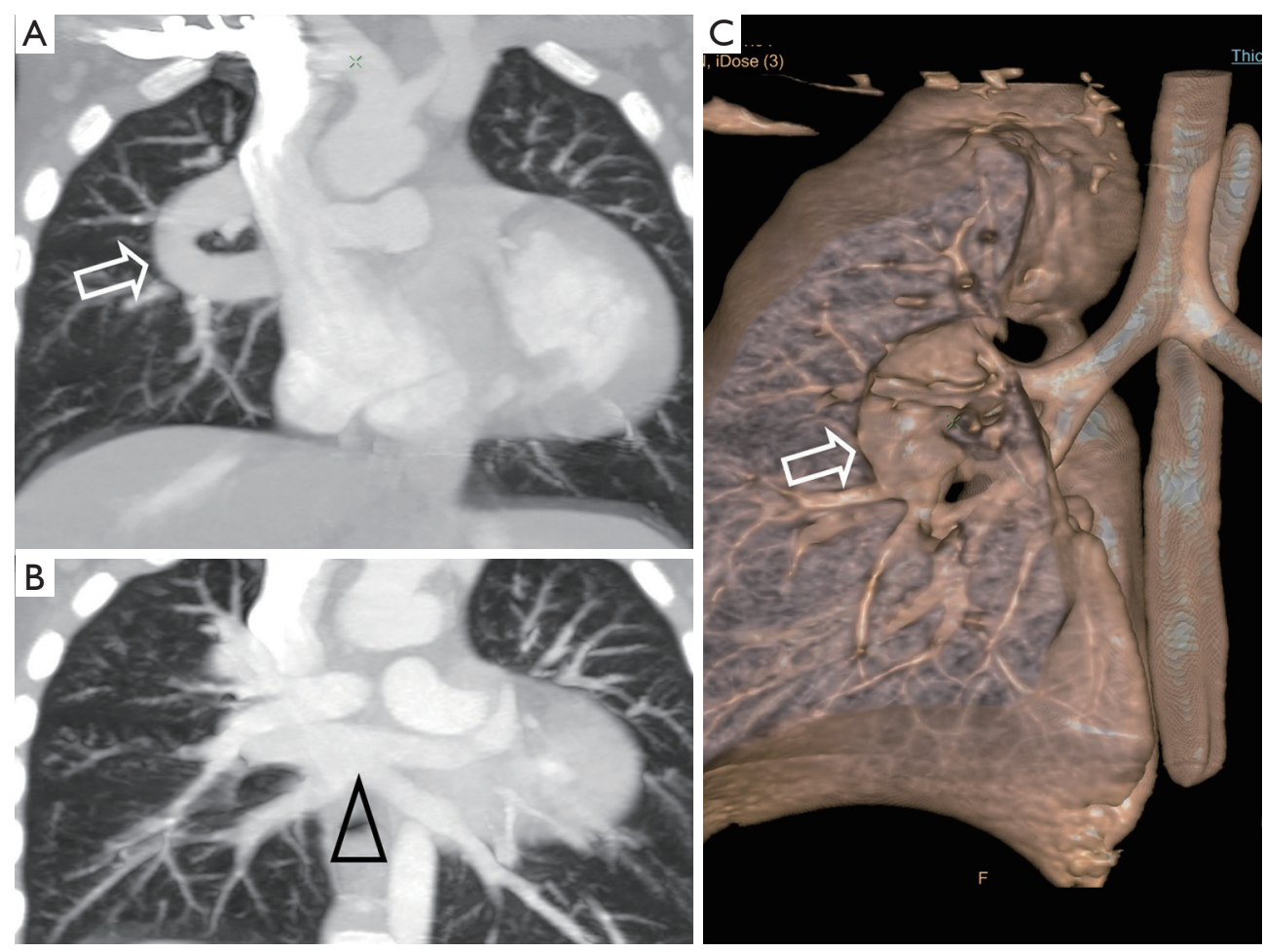

Figure 3 CT examination with maximal intensity projection in coronal orientation (A and B) shows intrapulmonary course of right vertical vein (open arrow) and confluence of pulmonary veins (black triangle). 3-D rendered image (C) shows intrapulmonary path of right vertical vein (open arrow).

vertical vein, homodynamic factors within the vein and any associated obstructive component or jet, while the vessel is crossing the midline. In our patients anomalous pulmonary vein connection was established through the right cardinal vein resulting in right vertical vein. Long segment of right vertical vein resulted in meandering course of the vessel before joining right SVC.

As a general observation, meandering vessels in the lungs can be attributed to either arterial or venous origin. They are noted in patients with arterial tortuosity syndrome, pulmonary vascular malformations and in cases of infradiaphragmatic pulmonary venous drainage (5). Vascular path demonstrated in our patients add to the list of unusual aetiology of variant vascular shadows. Differentiation of one from the others requires correlation with clinical context and detailed investigations using cross-sectional imaging modalities like CT or magnetic resonance imaging.

\section{Acknowledgements}

Authors would like to acknowledge Dr. Sejal Shah, Dr.
Shashiraj from pediatric cardiology services and Dr Devi Prasad Shetty, the Chairman of the hospital, for their respective contribution.

\section{Footnote}

Conflicts of Interest: The authors have no conflicts of interest to declare.

\section{References}

1. Geva T, Van Praagh S. Anomalies of the pulmonary veins. In: Allen HD, Driscoll DJ, Shaddy RE, Feltes TF, editors. Moss and Adams' Heart Disease in infants, children, and adolescents: Including the fetus and young adults. 7th ed. Philadelphia: Lippincott Williams and Wilkins, 2008:762.

2. Alp H, Baysal T, Karaarslan S. Unusual Form of a Supracardiac Type Total Anomalous Pulmonary Venous Connection. Cath lab Digest 2013;21. Available online: http://www.cathlabdigest.com/articles/Unusual-FormSupracardiac-Type-Total-Anomalous-Pulmonary-Venous- 


\section{Connection}

3. Lehner A, Kozlik-Feldmann R, Herrmann F, et al. An unusual form of supracardiac total anomalous pulmonary venous return via a right-sided vertical vein in a heterotaxy syndrome case. Pediatr Cardiol 2012;33:1200-2.

4. Kalantre AA, Champaneri B, Kottayil B, et al.

"Hemodynamic vice" of the right-sided ascending vertical vein in the setting of supracardiac total anomalous pulmonary venous connection in a neonate: Anatomicembryological correlation. Ann Pediatr Cardiol 2017;10:104-6.

5. Bhat $\mathrm{V}, \mathrm{Al}$ Muzrakchi A. Meandering vessels: A sign of arterial tortuosity on plain chest radiography. Heartviews 2008;9:24-6.
Cite this article as: Bhat V, Gadabanahalli K, Maiya S. Meandering vessel on a chest radiograph in a cyanotic neonate: rare presentation of intrapulmonary course of right vertical vein in patients with supracardiac total anomalous pulmonary venous connection. Quant Imaging Med Surg 2018;8(4):447-451. doi: 10.21037/qims.2018.04.04 